\title{
Flow characteristics of Roots pumps with multistage designs by CFD investigation
}

\author{
Chiu-Fan HsieH ${ }^{\mathrm{a}}$
}

Department of Mechanical and Computer-Aided Engineering, National Formosa University, 64 Wunhua Road, Huwei, Yunlin, Taiwan, R.O.C.

Received 8 January 2014, Accepted 31 March 2015

\begin{abstract}
This study conducts a fluid analysis of multistage designs for a Roots pump, a type of positive displacement pump applied in blower and vacuum pumps. After a rotor profile is generated based on a mathematical model of a rotor, a three-dimensional numerical approach is developed using computational fluid dynamics (CFD) and applied to investigate the effect of multistage pump design on flow characteristics. The effects of serial versus parallel designs on fluid are illustrated using a two-lobed rotor. The fluid analysis, which pays particular attention to favorable stages, shows that in both serial and parallel connection designs, having more than three stages improves flow characteristics but to a relatively small degree because of increased leakage. It identifies the three-stage design as offering the greatest economy for pumping performance enhancement. A similar analysis is then performed on a three-lobed rotor design using the same three-stage design. A comparison of the flow characteristics of the two- versus three-lobed rotors based on serial versus parallel design and identical chamber volume identifies specific variations in flow rate, pressure, and pulsation.
\end{abstract}

Key words: Roots pump / gear / fluid / CFD

\section{Introduction}

The Roots pump, an air-extracting apparatus, is a type of positive displacement pump that can be used in blower or vacuum pumps. In both applications, the Roots pump employs a pair of rotors with two or more lobes that are driven by a pair of timing gears (Fig. 1). These two rotors, which are used mainly for pneumatic conveyance, rotate with a constant gear ratio in opposite directions, maintaining tiny clearances during operation and drawing in air from one side to deliver to the other. These rotors are useful for vacuum exhausting in semiconductor fabrication equipment, particularly in new or high-technology industries like photonics, lasers, vacuum heat treatment, nuclear research, precision manufacturing, or national defence technology. When their pumping efficiency is high, they remain in better working condition, which improves product quality.

In the literature on the Roots pump, numerous authors have advanced aspects of rotary pump design theory, including a rotor's geometric design [1], profile generation and avoidance of undercutting [2], new design methods for rotor profiles, and analyses for improving volumetric efficiency and sealing properties [3-8].

\footnotetext{
${ }^{a}$ Corresponding author: cfhsieh@nfu.edu.tw
}

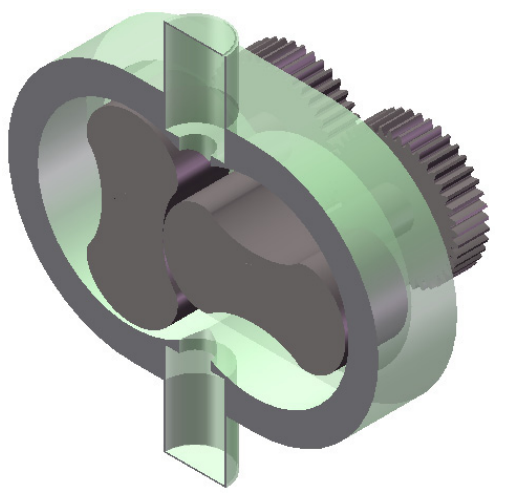

Fig. 1. Roots pump.

They have also proposed a method (the semi-empirical Knudsen-Dong law) for predicting internal leaks [9] and an angular coefficients method for calculating channel conductance [10].

For flow simulation, Houzeaux et al. [11] developed a finite element method for the simulation of rotary positive displacement pumps, while Strasser [12] used a commercial computational fluid dynamics (CFD) solver, FLUENT, to simulate the gear pump. Subsequently, 
Del Campo et al. [13] used FLUENT to carry out a fluid analysis of external gear pump including cavitation and analyzed the influence of the pump's rotational speed. These studies [11-13], however, primarily developed twodimensional numerical approaches using CFD or CFD tools for the involute external gear pump. Hence, although industry commonly uses Roots pumps with a multistage design, no surveys or papers have applied a threedimensional numerical approach to the Roots pump's flow performance.

To address this research void, this paper develops a three-dimensional fluid analysis model of multistage Roots pumps and then uses it to analyze their flow characteristics. It then uses a two-lobed rotor to illustrate the effects of serial versus parallel design on fluid flow, with particular attention to differences, including a leakage forecast analysis, and favourable design stages. To open a discussion on multistage design and improved pumping efficiency, it next investigates a three-lobed rotor design and then compares the flow characteristics of two- versus three-lobed rotors based on serial/parallel design and identical chamber volume. The fluid analysis models used are outlined and discussed below.

\section{Computational model and method}

The fluid analysis model is constructed using the new commercial CFD package PumpLinx, whose efficacy has been shown by comparing simulation and experimental results for various fluid machinery [14]. To conduct a CFD analysis of a Roots pump, a CAD model must first be created by stipulating the rotor geometry design and then meshing the geometry with the program grid generator.

PumpLinx solves conservation equations of mass and momentum using a finite volume discretization method with SIMPLE algorithm for the velocity-pressure coupling. In particular, the numerical method is second-order upwind for discretization of partial differential equations (PDE), conjugate gradient squared (CGS) for momentum equation matrix, and algebraic multi-grid (AMG) for pressure equation matrix. Besides, time accuracy is first-order discretized. The pressure term is upwind; the viscous term (or called diffusion term) is central difference and advection term (or called convection term) is second-order upwind.

\subsection{Assumptions and boundary conditions}

The boundary and operation conditions are as follows: the fluid used is air (dynamic viscosity $=1.853 \mathrm{e}-05$ Pa.s), which is treated as a compressible fluid whose density is dependent on the local pressure and temperature. In CFD simulation, therefore, the density is not constant. The inlet pressure is one atmospheric pressure $(101.325 \mathrm{kPa})$, the outlet operation pressure is $150 \mathrm{kPa}$, the clearance value between the rotor and chamber and between the two rotors is $0.6 \mathrm{~mm}$, and the rotor rotation speed is $3000 \mathrm{rpm}$.

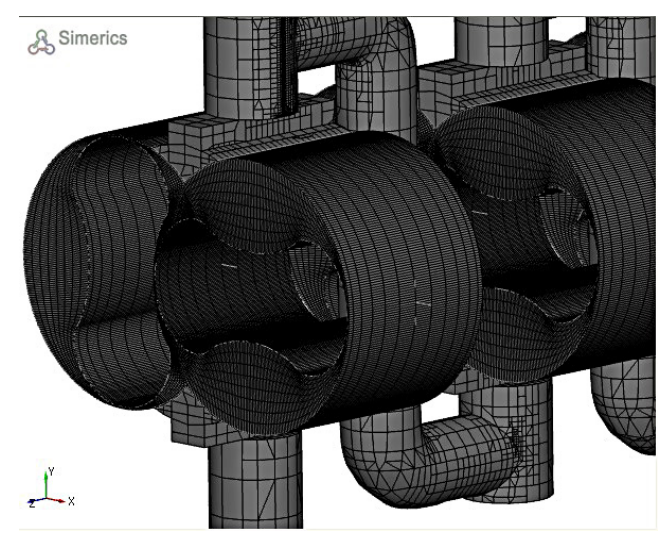

(a)

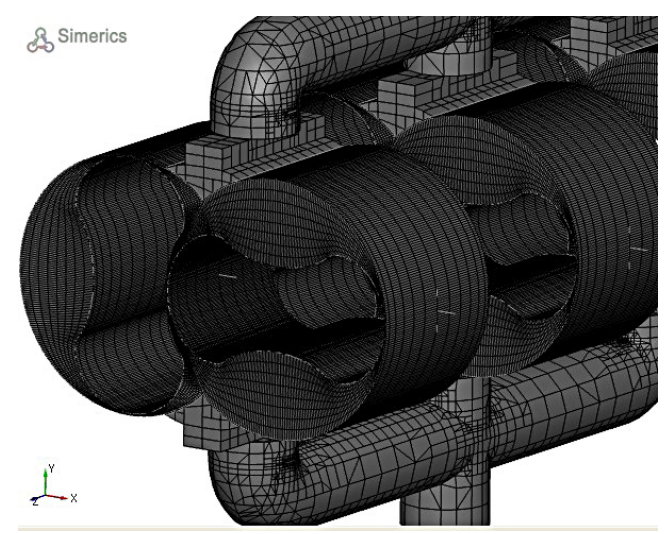

(b)

Fig. 2. Pump mesh. (a) Serial connection. (b) Parallel connection.

The left rotor rotates clockwise, and the right rotor rotates counter-clockwise. The radius of the pipes is $20 \mathrm{~mm}$. In each stage, the chamber volume, set at $1600 \mathrm{~cm}^{3}$ is the same no matter whether the design is serial or parallel. Besides, the fluid analysis also makes the following important assumptions:

(1) The fluid is analyzed using a turbulent model $(k-\varepsilon$ model).

(2) Flow is unsteady, compressible, and turbulent.

\subsection{Grid generation and calculation}

PumpLinx grids use a body-fitted binary tree approach that employs moving mesh (or dynamic grid) and mismatched grid interface (MGI) algorithmic techniques to reduce the calculation time and derive the exact analytic value [14]. Figure 2 shows the grid differences between stationary (inlet outlet and pipes) and moving parts (rotors) in three-stage pumps design. In the boundary layer the grid density on the surface has increased. In the regions of high curvature and small spaces, the grid has been subdivided and cut to conform to the surface. From conformal adaptive binary-tree meshing technology, in the evaluation of mesh density, even a tiny gap on the 
Table 1. Grid independence test for 2-lobe rotors with three-stage serial connection.

\begin{tabular}{|c|c|c|c|}
\hline & eps per gearing cycle $=80$ & Time steps per gearing cycle $=160$ & Time steps per gearing cycle $=240$ \\
\hline cells $=241168$ & Average flo & Ave &. $\left.\mathrm{s}^{-1}\right)$ \\
\hline cells $=242216$ & Average flowrate $=0.02453\left(\mathrm{~kg} . \mathrm{s}^{-1}\right)$ & Average flowrate $=0.02471\left(\mathrm{~kg} \cdot \mathrm{s}^{-1}\right)$ & Average flowrate $=0.02482\left(\mathrm{~kg} . \mathrm{s}^{-1}\right)$ \\
\hline
\end{tabular}

Table 2. Grid and geometry information.

\begin{tabular}{ccccc}
\hline Series design & 2-lobe 2-stage & 2-lobe 3-stage & 2-lobe 4-stage & 3-lobe 3-stage \\
\hline Number of cells & 162813 & 242216 & 317852 & 238490 \\
Number of faces & 531535 & 792160 & 1037958 & 775811 \\
Number of nodes & 202716 & 302106 & 394962 & 295 170 \\
\hline Parallel design & 2-lobe 2-stage & 2-lobe 3-stage & 2-lobe 4-stage & 3-lobe 3-stage \\
\hline Number of cells & 173422 & 240800 & 338072 & 251403 \\
Number of faces & 579751 & 784637 & 1108508 & 829192 \\
Number of nodes & 225554 & 298684 & 425757 & 320892 \\
\hline
\end{tabular}

contact surface can be calculated. In this mesh result, the volume variation space between the two rotors and the chamber has a higher grid density, while the inlet, outlet and pipes spaces have a lower grid density.

First, the grid size independence test and time step size independence test should be done. Let us take 2-lobe rotors with three-stage serial connection as example. As shown in Table 1, an acceptable accuracy with the maximum grid size and time step size (that is, the minimum grid amount and minimum time steps amount) can be obtained to save the required numerical resource. The error is reduced from 160 steps to 240 steps. So, this case uses 320 time steps per gearing cycle and cells is 242216 (acceptable grid size) for a more accurate simulation. Based on this approach, for all cases tested in this paper, the grid and geometry information are as shown in Table 2.

For Roots pumps, it is necessary to use a moving/sliding methodology whereby the stationary and moving volumes are meshed separately. Each moving volume connects to the others via a common interface, which, because of deformations and motion, is updated at each time step. Hence, as the rotor rotates, the dynamic grid automatically performs calculations (an update at each time-step) and can thus calculate the entire variation in pressure, flowrate, and flow velocity over time. For example, when the two rotors rotate at a certain angle, the pocket volume changes and the grid can be calculated automatically. As Figures $3 \mathrm{a}$ and $3 \mathrm{~b}$ show, the grid is generated dynamically through pressure calculations for the serial and parallel connections, respectively, which produces more accurate results.

\section{Results and discussion}

The following results were derived for 2 to 6 cycles (rotor revolutions) before flows reached a periodic steady state, with the data obtained based on one revolution of the rotor.

\subsection{The influence of serial design on pumping}

Figure 4 shows the results of the pressure computations for the two- to four-stage two-lobed rotors in a serial connection. In each multistage serial design, the pressure progressively increases from one stage to the next, with the highest pressure in the region closest to the outlet. Hence, in all three serial designs, the pressure near the outlet is higher than that at the inlet.

At the outlet, the flow data, including instantaneous flowrate, velocity, and pressure for maximum and minimum value in one revolution, are as shown in Table 3. To clearly illustrate the differences between the various multiple stage designs, this table also shows the average flowrate and flow ripple quantity, as well as their increments by percentage. Here, the flow ripple quantity is defined as the difference between the maximum and minimum value of the flow data, and the increment from twostage to three-stage is defined as follows:

$$
\frac{M_{3 \text {-stage }}-M_{2 \text {-stage }}}{\mathrm{M}_{2 \text {-stage }}} \times 100 \%
$$

where $M$ represents such characteristics as the average flowrate or flow ripple quantity.

The increment from the three-stage to four-stage design is then determined by

$$
\frac{M_{4 \text {-stage }}-M_{3 \text {-stage }}}{M_{2 \text {-stage }}} \times 100 \%
$$

When the flowrate is positive, the direction of the flow is out from outlet, and when it is negative, the flow is in the opposite direction. As Table 3 shows, there is reverse flow (a negative flowrate) in the two-stage design but not in the three- and four-stage designs. Moreover, although the maximum value of instantaneous flowrate is similar in the three- and four-stage designs, these values are both significantly higher than that in the two-stage design. The minimum value of the instantaneous flowrate also indicates that, for the three- and four-stage designs, 
Chiu-Fan Hsieh: Mechanics \& Industry 16, 601 (2015)

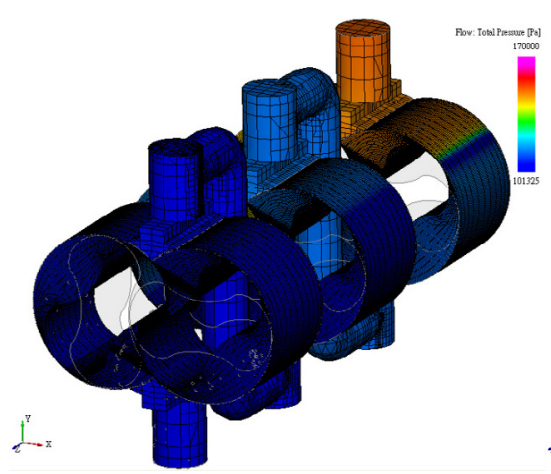

$0.0125 \mathrm{~s}$

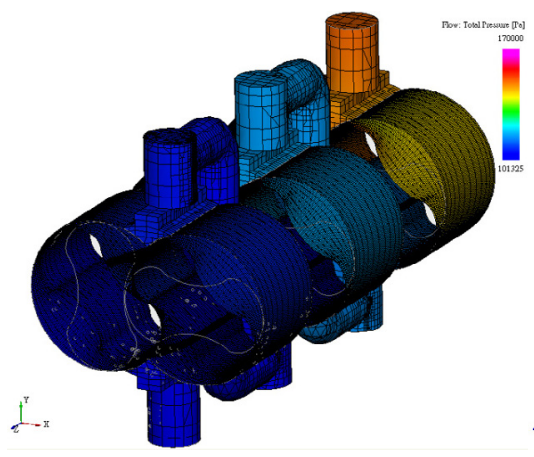

$0.0175 \mathrm{~s}$

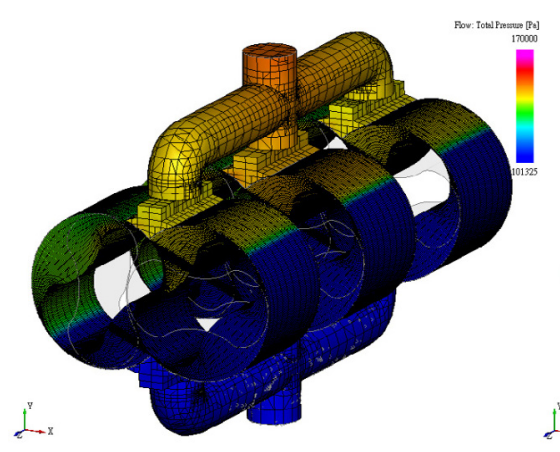

$0.0125 \mathrm{~s}$

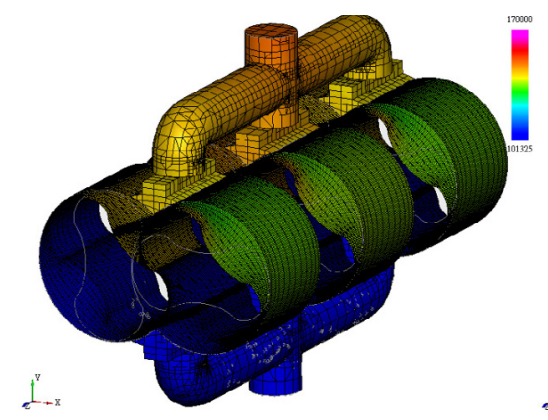

$0.0175 \mathrm{~s}$

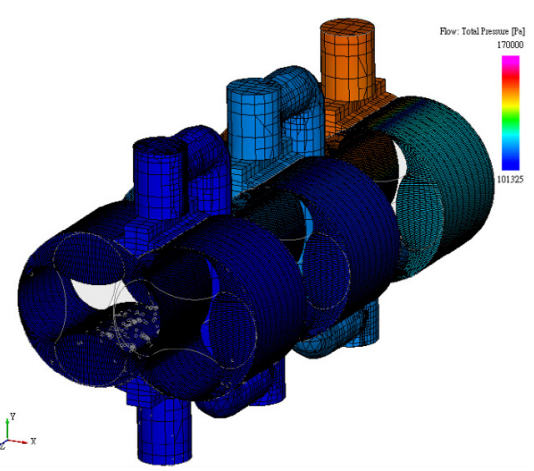

$0.015 \mathrm{~s}$

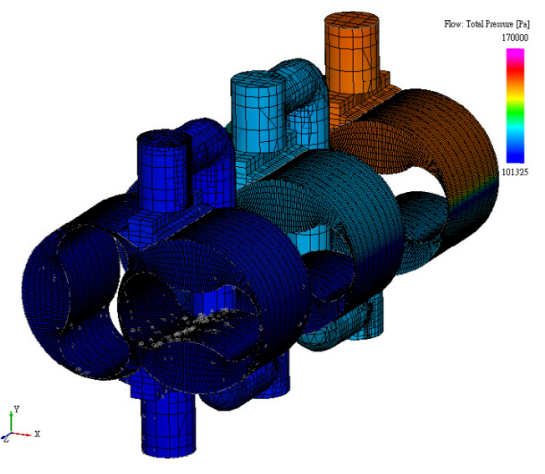

$0.02 \mathrm{~s}$

(a)

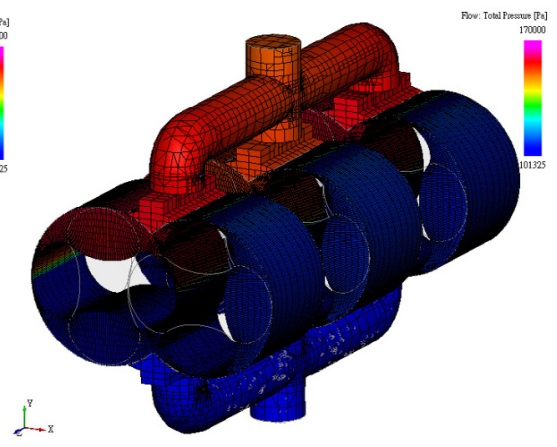

$0.015 \mathrm{~s}$

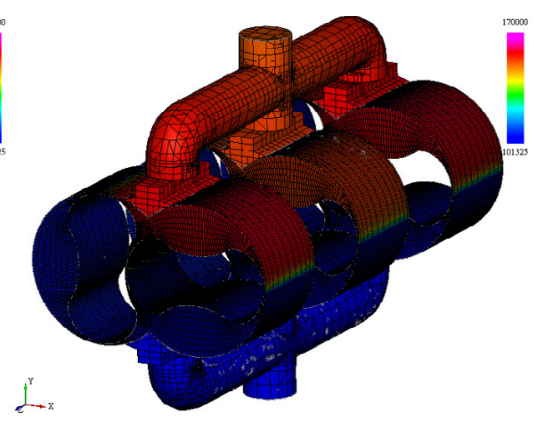

$0.02 \mathrm{~s}$

(b)

Fig. 3. Grid and pressure calculations. (a) Serial connection. (b) Parallel connection. 


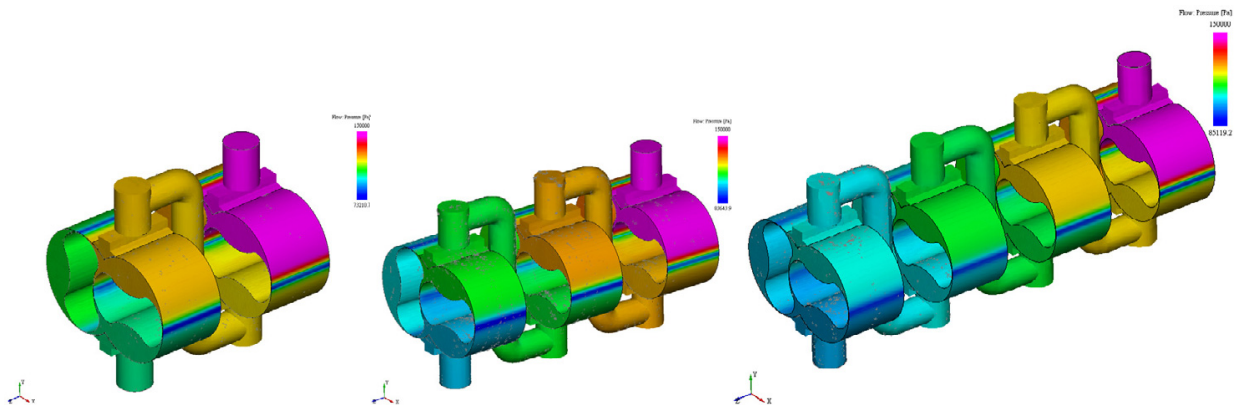

Fig. 4. 2-4 stage serial connections for 2-lobe rotors.

Table 3. CFD results for 2-lobe rotors with multiple stage serial connections.

\begin{tabular}{|c|c|c|c|c|c|}
\hline & 2 -stage & 3-stage & 4-stage & $\begin{array}{c}2 \text { to } 3 \text { stage } \\
\text { increment }(\%)\end{array}$ & $\begin{array}{c}3 \text { to } 4 \text { stage } \\
\text { increment }(\%)\end{array}$ \\
\hline Average flowrate (kg.s $\left.{ }^{-1}\right)$ & 0.0199 & 0.0249 & 0.0275 & 25.3 & 12.78 \\
\hline Flowrate $Q_{\max }\left(\mathrm{kg} \cdot \mathrm{s}^{-1}\right)$ & 0.0502 & 0.0519 & 0.0533 & 3.38 & 2.81 \\
\hline Flowrate $Q_{\min }\left(\mathrm{kg} \cdot \mathrm{s}^{-1}\right)$ & -0.0106 & 0.0021 & 0.0081 & -119.79 & -56.42 \\
\hline $\begin{array}{l}\text { Flowrate ripple quantity }\left(\mathrm{kg} \cdot \mathrm{s}^{-1}\right) \\
\left(Q_{\max }-Q_{\min }\right)\end{array}$ & 0.0608 & 0.0498 & 0.0452 & -18.12 & -7.53 \\
\hline Flow velocity $V_{\max }\left(\mathrm{m} \cdot \mathrm{s}^{-1}\right)$ & 38.088 & 42.938 & 41.716 & 12.73 & -3.21 \\
\hline Flow velocity $V_{\min }\left(\mathrm{m}_{\mathrm{s}} \mathrm{s}^{-1}\right)$ & -0.678 & 8.230 & 9.301 & -1313.11 & -157.85 \\
\hline $\begin{array}{c}\text { Velocity ripple quantity }\left(\mathrm{m} \cdot \mathrm{s}^{-1}\right) \\
\left(V_{\max }-V_{\min }\right)\end{array}$ & 38.766 & 34.707 & 32.414 & -10.47 & -5.91 \\
\hline Pressure $P_{\max }(\mathrm{Pa})$ & 151987 & 151823 & 151622 & -0.11 & -0.13 \\
\hline Pressure $P_{\min }(\mathrm{Pa})$ & 148853 & 148757 & 148878 & -0.06 & 0.08 \\
\hline $\begin{array}{l}\text { Pressure ripple quantity }(\mathrm{Pa}) \\
\qquad\left(P_{\max }-P_{\min }\right)\end{array}$ & 3134 & 3066 & 2744 & -2.17 & -10.27 \\
\hline
\end{tabular}

the flowrate values are positive. Conversely, the flowrate value in the two-stage design is negative, which affects discharge efficiency.

This last observation implies that the flow capacity in the three- and four-stage designs is larger than in the two-stage design, meaning that a three- or four-staged design could more effectively enhance flowrate. Moreover, based on the ripple quantity (see Tab. 3), the amplitude of pulsation reduces as the number of stages increases, suggesting that a pump with more stages generates greater force for delivering fluid. However, from the two-stage to the three-stage design, the increment is $-18.12 \%$, a negative that indicates an $18.12 \%$ decrement. Likewise, from the three-stage to the four-stage design, the increment is $-7.53 \%$, indicating a $7.53 \%$ decrement. It should be noted that the decrement from the two-stage to the three-stage design is larger than that from the three-stage to the fourstage design.

In terms of average flowrate, the increment from the two-stage to the three-stage designs $(25.3 \%)$ is greater than that from the three-stage to the four-stage (12.78\%), implying that although the flowrate increases with an increasing number of stages, the increment gradually decreases. This decrease occurs because the additional friction in the airflow path generated between the interior wall and the rotor, as well as leakage, increases with the number of stages, which reduces efficiency.

Because the fluid passes through sections of inlet and outlet pipes in the direction of the $y$ axis, this analysis only addresses flow velocity in the $y$ direction. Based on the outlet flow velocity shown in Table 3, the maximum value of the three-stage design $\left(42.9 \mathrm{~m} . \mathrm{s}^{-1}\right)$ is higher than that of the four-stage design $\left(41.7 \mathrm{~m} . \mathrm{s}^{-1}\right)$. However, in both these designs, the value is greater than in the twostage design $\left(38.08 \mathrm{~m} . \mathrm{s}^{-1}\right)$, in which there is also reverse flow (negative velocity). Hence, the two-stage design produces less force for delivering fluid. Although this force increases in the four-stage design, the minimum value in this latter $\left(9.3 \mathrm{~m} . \mathrm{s}^{-1}\right)$ is near to that in the three-stage design (8.23 m.s), while the decrement in the flow velocity ripple quantity from the two-stage to the three-stage design $(10.47 \%)$ is larger than that from the three-stage to the four-stage design (5.91\%). These figures suggest that the four-stage design may cause excessive power loss and negatively affect flow performance.

Regarding outlet pressure, as Table 3 shows, the pressure peak decreases as the number of stages increases, so that increasing the number of stages may produce higher leakage and a $10.27 \%$ decrement in the pressure ripple quantity, especially from the three- to the four-stage design. Although this lower pressure fluctuation may reduce vibration, in designs with more than three stages, increases in pump performance are limited.

Based on the above results, pumping efficiency is reduced according to leakage level, with the main leakage paths being the clearance between the chamber and rotors and between the two rotors. Thus, in the estimation of leakage level, the pump is illustrated with three survey 
Chiu-Fan Hsieh: Mechanics \& Industry 16, 601 (2015)

Table 4. Leakage prediction analysis for serial connections.

\begin{tabular}{cccccc}
\hline & 2-stage & 3-stage & 4-stage & $\begin{array}{c}\text { 2 to 3 stage } \\
\text { increment (\%) }\end{array}$ & $\begin{array}{c}3 \text { to } 4 \text { stage } \\
\text { increment (\%) }\end{array}$ \\
\hline Average flow velocity $\left({\left.\mathrm{m} . \mathrm{s}^{-1}\right)}^{-1}\right)$ & -56.84 & -47.12 & -41.06 & -17.09 & -10.66 \\
Maximum flow velocity $\left(\mathrm{m} . \mathrm{s}^{-1}\right)$ & -270.93 & -245.28 & -230.08 & -9.47 & -5.61 \\
\hline
\end{tabular}

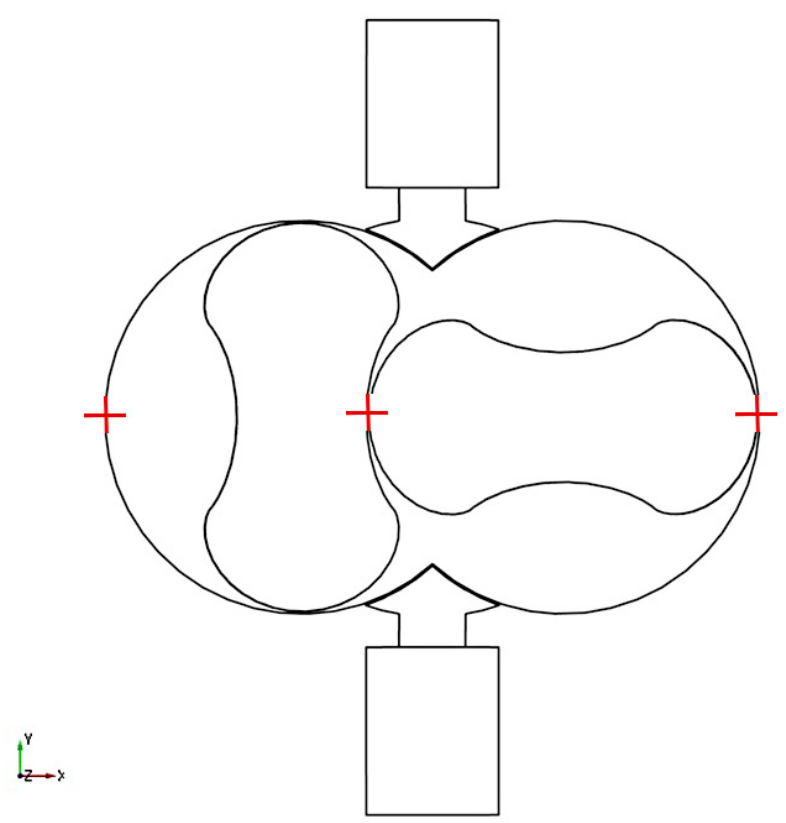

Fig. 5. Survey points.

points in each stage indicated by crossed lines (see Fig. 5). In Figure 6, these survey points and leakage paths confirm the existence of reverse or back flow in the pump. Specifically, the decrement of the reverse flow from the two-stage to the three-stage design is larger than that from the three-stage to the four-stage design no matter whether based on average flow velocity or maximum flow velocity (see Tab. 4). Hence, the above analysis clearly identifies the three-stage design, with its relatively lower leakage, as a better option for power economy.

\subsection{The influence of the parallel design on pumping}

Figure 7 provides a color illustration of pressure in the two- to four-stage two-lobed parallel connected rotors at a certain time. In these designs, the pressure close to the outlet side in each stage is relatively consistent and greater than that on the inlet side. In addition, as Table 5 shows, the average outlet flowrate suggests that flowrates increase as the number of stages increases. Nonetheless, the increment from the two-stage to the three-stage design $(34.3 \%)$ is greater than that from the three-stage to the four-stage design $(28.19 \%)$, suggesting that although the flowrate increases with stage number, the magnitude of the increase gradually decreases (albeit not in direct proportion). This decrease occurs because leakage increases as the number of stages increases and excessive power is lost through the pumping process. As a result, the efficiency increase in designs with three or more stages is limited by additional energy consumption.

In terms of instantaneous flowrate ripple (see Tab. 5), the maximum value is highest in the three-stage design but is close to that in the four-stage design. The minimum value, however, is negative, and the reverse flow in the three-stage design is greater than that in the four-stage design, indicating that the average flowrate in this latter is greater than that in the three-stage design. The maximum value is lowest in the two-stage design, which also has the highest negative quantity (largest reverse flow), leading to the smallest average flowrate. Hence, reverse flows occur in all three designs.

According to the outlet flow velocities, the maximum flow velocity also increases with number of stages. Because of the structure in the parallel design, the inlet or outlet of each stage pump is on the same side, in contrast to the serial design in which each is connected by way of one stage's outlet to the next stage's inlet. The velocity ripple quantity further indicates that the decrement from the two-stage to the three-stage design $(2.82 \%)$ is smaller than that from the three-stage to the four-stage design $(8.47 \%)$.

Because of the structural difference, this decrement is also different from that in the serial design. Most particularly, in the parallel design, each stage pump can simultaneously exert force on the fluid, forcing it in the positive direction along the $y$-axis (in the outlet direction), thereby reducing the flow in the negative direction. This parallel structure, however, also produces major reverse flow inside the pump. In the leakage prediction analysis, for example, the leakage paths clearly show reverse flow as shown in Figure 8. With additional stages, this reverse flow (or leakage level) increases by average or maximum flow velocity (see Tab. 6). However, the increment of the reverse flow from the two-stage to three-stage design is slightly larger than that from the three-stage to four-stage design no matter whether based on average or maximum flow velocity (see Tab. 6). These light increments indicate that in the parallel design, leakage levels increased are low.

According to Table 5, the pressure pulsations are greatest in the two-stage design as a result of undesired noise and vibration. Nevertheless, although the two-stage design has the highest maximal pressure value, it also has the minimal pressure value, exhibiting the lowest average pressure of all three designs. For the pressure ripple quantity, the decrement from the two-stage to the threestage design is $44.15 \%$ which implies stable pressure. However, from the three-stage to the four-stage design, the 

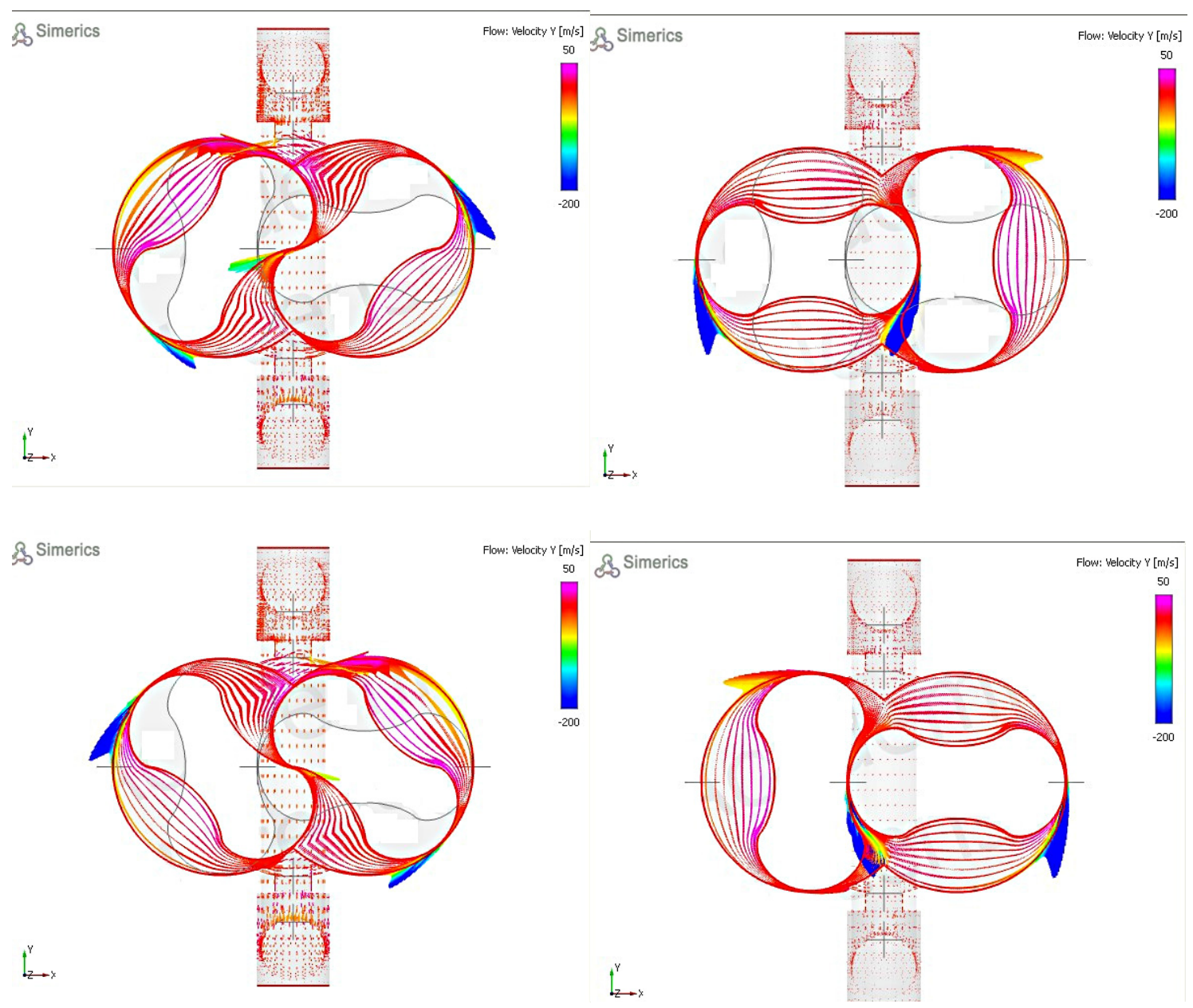

Fig. 6. Flow velocity in $Y$ vector for serial connections.

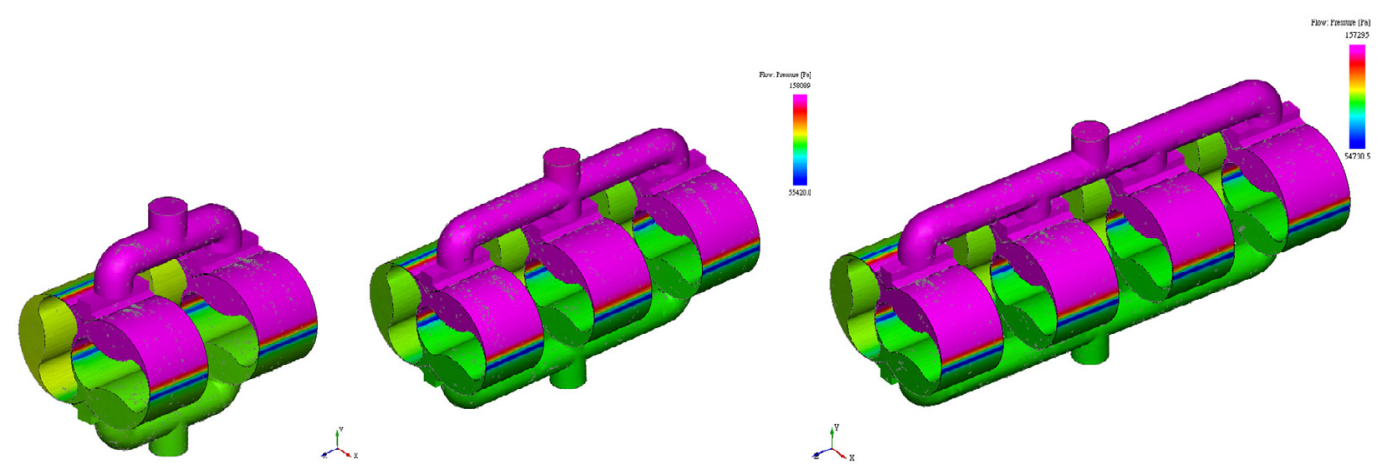

Fig. 7. 2-4 stage parallel connections for 2-lobe rotors.

increment is $11.11 \%$, which lower pressure stability. It is the three-stage design, therefore, that is the most stable.

Table 7 compares the difference in flow characteristics on the outlet side between the serial and parallel designs given a fixed stage. The results show that the average flowrate, its pulsations (or ripples), and the flow velocity are all greater in the parallel design than in the serial design, which also exhibits more reverse flow. However, the pressure ripples also indicate that the pulsations in the serial design are greater than in the parallel design except in the two-stage design. The three-stage parallel design, therefore, is the most stable on the outlet side and also has the best power economy.

The fluid analysis model is used in similar manner to calculate a three-staged three-lobed rotor with either serial or parallel connections whose pressure illustrations are given in Figure 9. Given the same number of stages (three), the analysis results are as reported in the next section where they are also compared with the results for the two-lobed rotor. 
Chiu-Fan Hsieh: Mechanics \& Industry 16, 601 (2015)

Table 5. CFD results for 2-lobe rotors with multiple stage parallel connections.

\begin{tabular}{cccccc}
\hline & 2-stage & 3-stage & 4-stage & $\begin{array}{c}\text { 2 to 3 stage } \\
\text { increment }(\%)\end{array}$ & $\begin{array}{c}\text { 3 to 4 stage } \\
\text { increment }(\%)\end{array}$ \\
\hline Average flowrate $\left(\mathrm{kg} . \mathrm{s}^{-1}\right)$ & 0.0213 & 0.0286 & 0.0346 & 34.31 & 28.19 \\
Flowrate $Q \max \left(\mathrm{kg} . \mathrm{s}^{-1}\right)$ & 0.0787 & 0.0904 & 0.0898 & 14.73 & -0.76 \\
Flowrate $Q \min \left(\mathrm{kg} . \mathrm{s}^{-1}\right)$ & -0.0718 & -0.0704 & -0.0508 & -1.97 & -27.24 \\
Flowrate ripple quantity $\left(\mathrm{kg} \cdot \mathrm{s}^{-1}\right)$ & 0.1506 & 0.1608 & 0.1406 & 6.77 & -13.39 \\
$\left(Q \max -Q_{\min }\right)$ & & & & & \\
Flow velocity $V_{\max }\left({\left.\mathrm{m} . \mathrm{s}^{-1}\right)}_{\text {Flow velocity } V_{\min }\left(\mathrm{m} . \mathrm{s}^{-1}\right)}\right.$ & 42.930 & 45.952 & 51.599 & 7.04 & 13.15 \\
Velocity ripple quantity $\left(\mathrm{m} . \mathrm{s}^{-1}\right)$ & 81.616 & 73.363 & -20.800 & -13.76 & -32.47 \\
$\quad\left(V_{\max }-V_{\min }\right)$ & & & & -2.82 & -8.47 \\
Pressure $P_{\max }(\mathrm{Pa})$ & 151054 & 150401 & 150774 & -0.43 & 0.25 \\
Pressure $P_{\min }(\mathrm{Pa})$ & 147210 & 148254 & 148200 & 0.71 & -0.04 \\
Pressure ripple quantity $(\mathrm{Pa})$ & 3844 & 2147 & 2574 & -44.15 & 11.11 \\
$\quad\left(P_{\max }-P_{\min }\right)$ & & & & \\
\hline
\end{tabular}

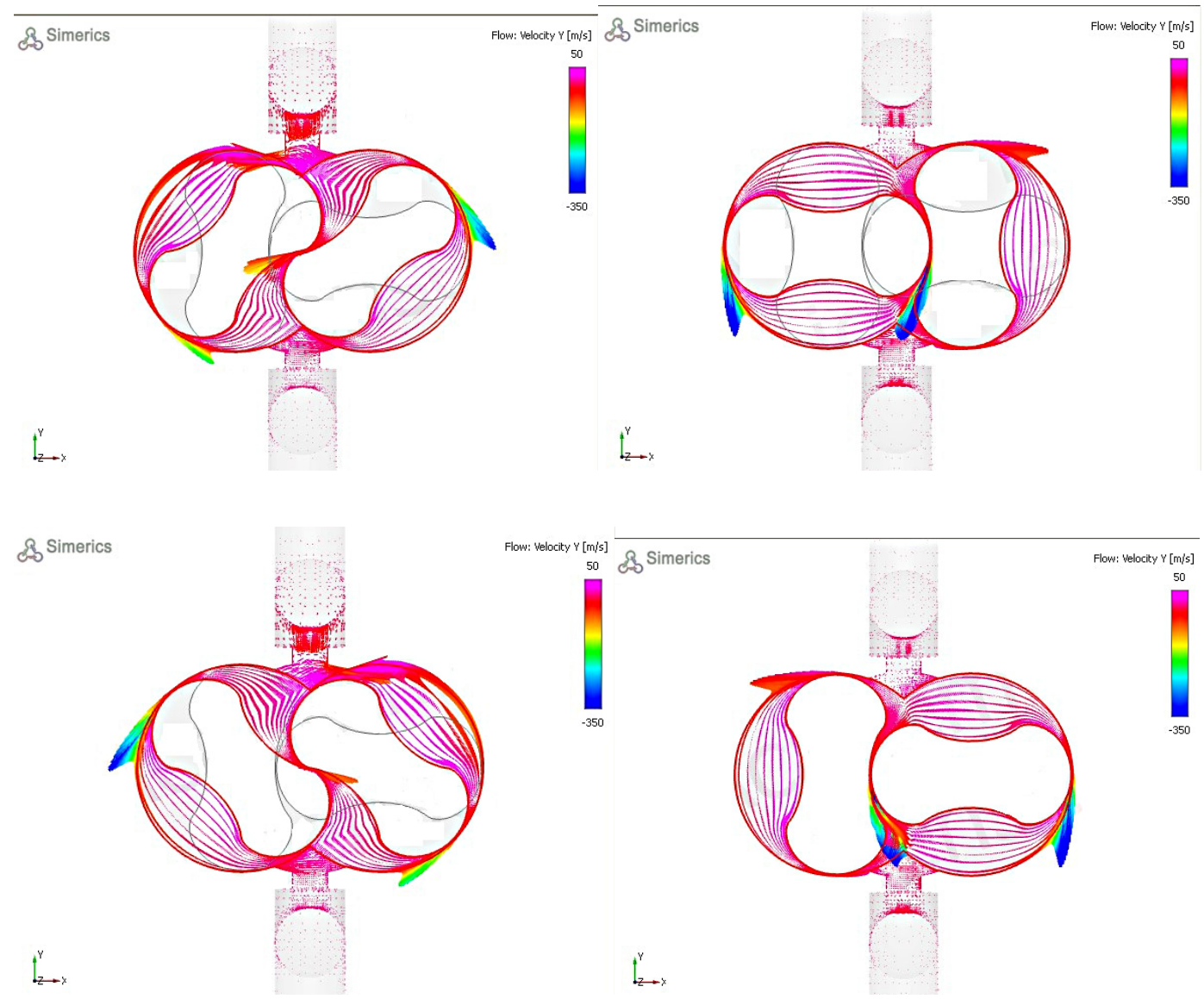

Fig. 8. Flow velocity in $\mathrm{Y}$ vector for parallel connections.

Table 6. Leakage prediction analysis for parallel connections.

\begin{tabular}{cccccc}
\hline & 2-stage & 3-stage & 4-stage & $\begin{array}{c}\text { 2 to 3 stage } \\
\text { increment }(\%)\end{array}$ & $\begin{array}{c}3 \text { to } 4 \text { stage } \\
\text { increment }(\%)\end{array}$ \\
\hline Average flow velocity $\left({\left.\mathrm{m} . \mathrm{s}^{-1}\right)}^{-1}\right)$ & -72.85 & -74.15 & -74.95 & 1.78 & 1.11 \\
Maximum flow velocity $\left(\mathrm{m} . \mathrm{s}^{-1}\right)$ & -363.18 & -372.66 & -375.42 & 2.61 & 0.76 \\
\hline
\end{tabular}



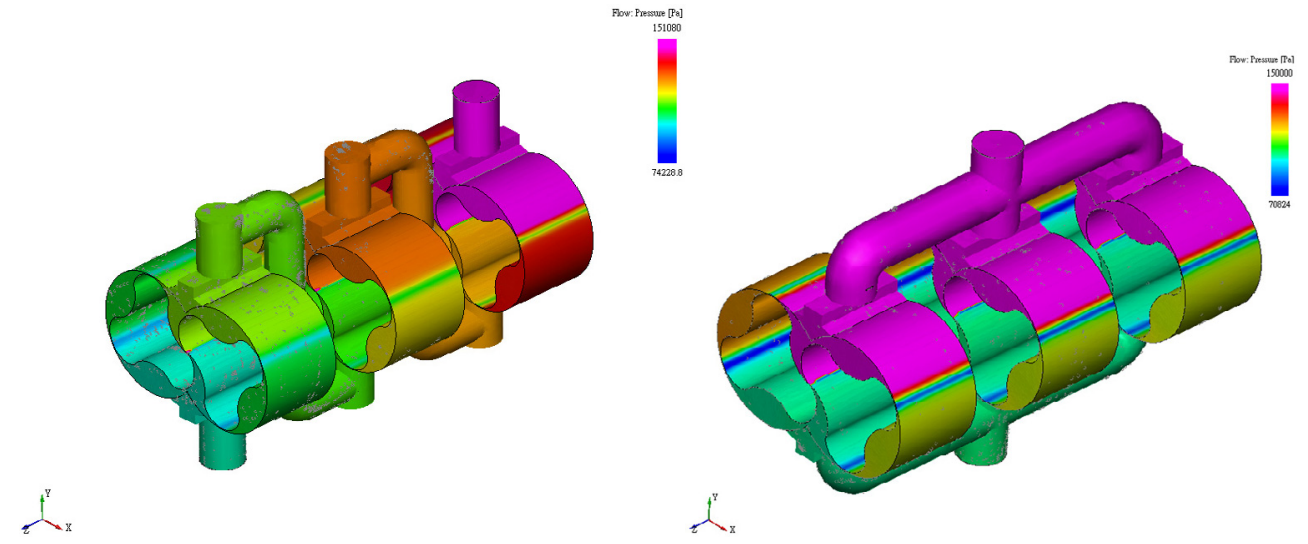

Fig. 9. Three-stage serial and parallel connections for 3-lobe rotors.

Table 7. Comparison of serial and parallel designs.

\begin{tabular}{cccc}
\hline & 2-stage serial vs. & 3-stage serial vs. & 4-stage serial vs. \\
& 2-stage parallel & 3-stage parallel & 4-stage parallel \\
\hline Average flowrate increment (\%) & 6.99 & 14.68 & 25.91 \\
Flowrate ripple quantity increment (\%) & 147.54 & 222.79 & 210.88 \\
Velocity ripple quantity increment (\%) & 110.53 & 128.53 & 123.35 \\
Pressure ripple quantity increment (\%) & 22.65 & -29.97 & -6.20 \\
\hline
\end{tabular}

Table 8. CFD results for 3-lobe rotors with three stages.

\begin{tabular}{cccc}
\hline & Serial & Parallel & Serial to parallel increment (\%) \\
\hline Average flowrate $\left(\mathrm{kg} . \mathrm{s}^{-1}\right)$ & 0.014 & 0.016 & 13.6 \\
Flowrate $Q_{\max }\left(\mathrm{kg} \cdot \mathrm{s}^{-1}\right)$ & 0.055 & 0.060 & 10.35 \\
Flowrate $Q_{\min }\left(\mathrm{kg} . \mathrm{s}^{-1}\right)$ & -0.031 & -0.038 & 22.43 \\
$Q_{\max }-Q_{\min }\left(\mathrm{kg} \cdot \mathrm{s}^{-1}\right)$ & 0.086 & 0.098 & 14.71 \\
Flow velocity $V_{\max }\left(\mathrm{m} . \mathrm{s}^{-1}\right)$ & 37.997 & 31.525 & -17.03 \\
Flow velocity $V_{\min }\left(\mathrm{m} . \mathrm{s}^{-1}\right)$ & -9.493 & -16.328 & 72.00 \\
$V_{\max }-V_{\min }$ & 47.490 & 47.853 & 0.76 \\
Pressure $P_{\max }(\mathrm{Pa})$ & 152921 & 150347 & -1.68 \\
Pressure $P_{\min }(\mathrm{Pa})$ & 147687 & 149333 & 1.11 \\
$P_{\max }-P_{\min }(\mathrm{Pa})$ & 5234 & 1014 & -80.63 \\
\hline
\end{tabular}

\subsection{Comparison of flow characteristics in three-stage designs with serial versus parallel connections}

In Tables 3, 5 and 8, regardless of whether the design is two-lobed or three-lobed, the average flowrates for parallel connections are greater than those for serial connections. The relative magnitude relation is two-lobed parallel $\left(0.0286 \mathrm{~kg} . \mathrm{s}^{-1}\right)>$ two-lobed serial $\left(0.0249 \mathrm{~kg} . \mathrm{s}^{-1}\right)>$ three-lobed parallel $\left(0.016 \mathrm{~kg} . \mathrm{s}^{-1}\right)>$ three-lobed serial $\left(0.014 \mathrm{~kg} . \mathrm{s}^{-1}\right)$. This relation indicates that the flowrate is mainly determined by delivery volume per rotor revolution. Likewise, regardless of whether the design is serial or parallel, the pocket volume (between the housing and two adjacent lobes) of the two-lobed rotor is greater than that of the three-lobed rotor.

The relation of flowrate ripple magnitude, on the other hand, is two-lobed parallel $\left(0.1608 \mathrm{~kg} . \mathrm{s}^{-1}\right)>$ three-lobed parallel $\left(0.098 \mathrm{~kg} . \mathrm{s}^{-1}\right)>$ three-lobed serial $\left(0.086 \mathrm{~kg} . \mathrm{s}^{-1}\right)$ $>$ two-lobed serial $\left(0.0498 \mathrm{~kg} \cdot \mathrm{s}^{-1}\right)$. The relation of pulsation magnitude in the outlet flow velocity is the same as that for the flowrate ripple. These results indicate that the flowrate and flow velocity ripples for the serial connections are lower than those for the parallel connections, regardless of whether the design is two-lobed or three-lobed.

The difference in flow ripple is plainly demonstrated in Table 9, in which the two-lobed parallel connection design exhibits the largest flow pulsations. Clearly, the threelobed parallel connection design could improve on the drawbacks in the two-lobed parallel connection design. Moreover, among the serial designs, the two-lobed serial connection has the smallest pulsation: when the lobe number increases to three, the flow ripple increases.

In fact, the comparison of the outlet pressure ripple in Figure 10 indicates that the pressure pulsations under serial connections are all greater than those under parallel connections, with the greatest pulsations and peak values occurring in the three-lobed serial connection design. The pressure curve in the parallel connection design not only displays smaller pulsations, it also stabilizes near a certain value for a relatively longer period (quasitrapezoidal pressure waveform), exhibiting an overall stable pressure. Here, the three-lobed parallel connection 


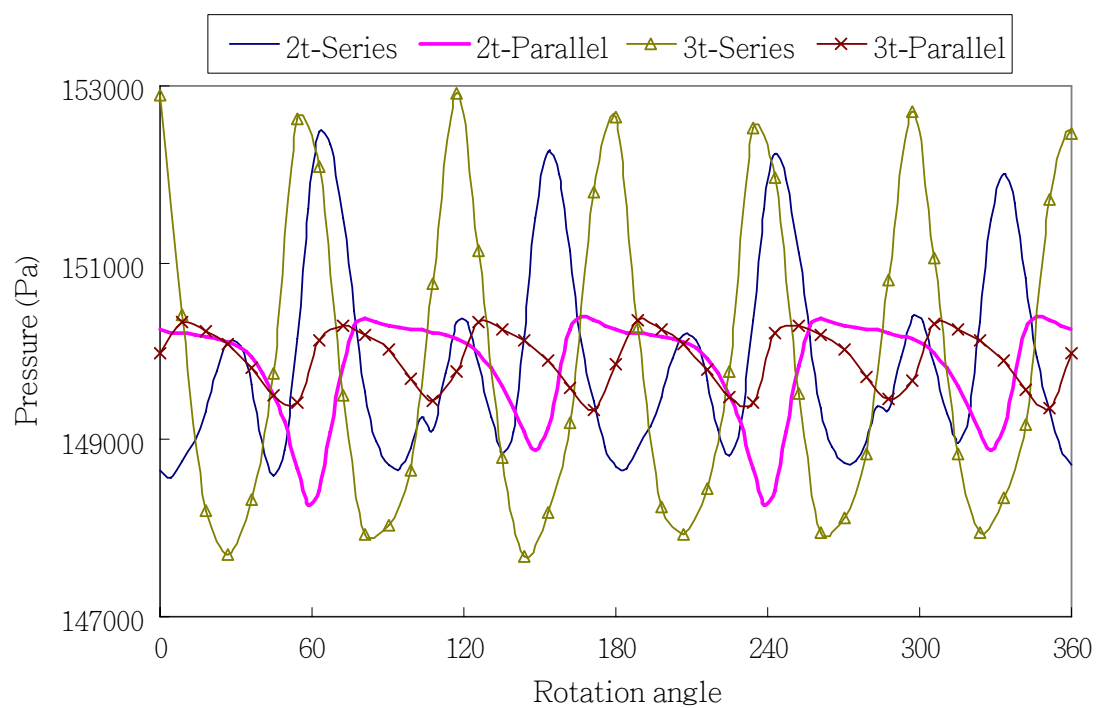

Fig. 10. Pressure in the three stages for 2-lobe and 3-lobe rotors.

Table 9. Comparison of 2-lobe and 3-lobe rotors.

\begin{tabular}{ccc}
\hline & $\begin{array}{c}\text { 2-lobe serial vs. 2-lobe parallel vs. } \\
\text { 3-lobe serial }\end{array}$ & 3-lobe parallel \\
\hline $\begin{array}{c}\text { Average flowrate } \\
\text { increment (\%) }\end{array}$ & -42.09 & -42.90 \\
$\begin{array}{c}\text { Flowrate ripple quantity } \\
\text { increment (\%) }\end{array}$ & 71.81 & -38.94 \\
$\begin{array}{c}\text { Velocity ripple quantity } \\
\text { increment (\%) }\end{array}$ & 36.83 & -40.30 \\
$\begin{array}{c}\text { Pressure ripple quantity } \\
\text { increment (\%) }\end{array}$ & 70.71 & -52.77 \\
\hline
\end{tabular}

obtains the smallest fluctuation and offers better performance in pressure stability.

\section{Conclusions}

This study first developed a fluid analysis model for multistage Roots pumps, and then, using multiple stage two-lobed rotors as an example, investigated the effects on pump fluid of serial and parallel connection designs with two to four stages. The fluid analysis results showed that in both serial and parallel connection designs, the three-stage design has the greatest economy for pumping performance enhancement. For designs with more than three stages, although the flow characteristics were still improved, the degree of improvement was relatively less significant because of increased leakage. Comparisons of the serial and parallel connections further showed that parallel connections produce larger average flowrates but higher flow pulsations than the serial design, meaning that the parallel design may more easily generate noise. As regards pressure, the pulsations in the parallel connections were relatively smaller and more stable.

Additional comparisons of the two-lobed and threelobed rotors under the same three-stage design indicated that the two-lobed parallel connection offers the greatest average flowrate, whereas the three-lobed serial connection produce the lowest average flowrate. The flow ripple in the parallel design was greater than that in the serial design, which could lead to more noise. However, the pressure ripple in the parallel design was smaller than that in the serial design, producing relative stability. Taken together, the analytic results can serve as a useful reference to the power economy and pumping efficiency for designing better multistage pumps in the future.

\section{Appendix}

The mathematical models of rotor geometry used in this paper can be summarized as follows.

The equation of the addendum curve can be rewritten as $[8]$

$$
\mathbf{r}_{1}=\left[\begin{array}{l}
x_{1} \\
y_{1} \\
1
\end{array}\right]=\left[\begin{array}{l}
r_{\mathrm{b}}[(2 n+1) \cos \theta-\cos (2 n+1) \theta] \\
r_{\mathrm{b}}[(2 n+1) \sin \theta-\sin (2 n+1) \theta] \\
1
\end{array}\right]
$$

where $r_{\mathrm{b}}$ is the radius of the rolling circle and $n$ is the number of the rotor lobe.

The equation of the dedendum curve can be rewritten as $[8]$

$$
\mathbf{r}_{2}=\left[\begin{array}{l}
x_{2} \\
y_{2} \\
1
\end{array}\right]=\left[\begin{array}{c}
(2 n+1) r_{\mathrm{b}} \cos (2 \phi-\theta) \\
-r_{\mathrm{b}} \cos (2 \phi-2 \theta-2 n \theta)-4 n r_{\mathrm{b}} \cos \phi \\
(2 n+1) r_{\mathrm{b}} \sin (\theta-2 \phi) \\
+r_{\mathrm{b}} \sin (2 \phi-2 \theta-2 n \theta)+4 n r_{\mathrm{b}} \sin \phi \\
1
\end{array}\right]
$$

Generation of the dedendum curve should consider the mesh equation as follows:

$$
\begin{aligned}
2 n \sin (\phi-\theta)-2 n & \sin [\phi-(2 n+1) \theta] \\
& +2 n \sin [\theta-(2 n+1) \theta]=0
\end{aligned}
$$

The design parameters are as shown in Table 10. 
Table 10. Design parameters.

\begin{tabular}{ll}
\hline \multicolumn{1}{c}{ 2-lobe rotor } & \multicolumn{1}{c}{ 3-lobe rotor } \\
\hline$r_{\mathrm{b}}=9.78 \mathrm{~mm}, r_{\mathrm{p}}=39.12 \mathrm{~mm}$ & $r_{\mathrm{b}}=7.13 \mathrm{~mm}, r_{\mathrm{p}}=42.8 \mathrm{~mm}$ \\
$C=78.24 \mathrm{~mm}, R=58.68 \mathrm{~mm}$ & $C=85.6 \mathrm{~mm}, R=57.06 \mathrm{~mm}$ \\
$A_{\text {chamber }}=20000 \mathrm{~mm}^{2}, A_{\text {rotor }}=5408.84 \mathrm{~mm}^{2}$ & $A_{\text {chamber }}=20000 \mathrm{~mm}^{2}, A_{\text {rotor }}=6074.39 \mathrm{~mm}^{2}$ \\
\hline
\end{tabular}

Acknowledgements. The author would like to thank Mr. Hong, Z.W. for his partial assistance with the fluid simulation.

\section{References}

[1] F.L. Litvin, P.H. Feng, Computerized Design and Generation of Cycloidal Gearings, Mech. Mach. Theory 31 (1996) 891-911

[2] G. Mimmi, P. Pennacchi, Analytical Model of a Particular Type of Positive Displacement Blower, Proc. IMechE, Part C: J. Mech. Eng. Sci. 213 (1999) 517-526

[3] H.C. Liu, S.H. Tone, D.C.H. Yang, Trapping-Free Rotors for High-Sealing Lobe Pumps, ASME J. Mech. Des. 122 (2000) 536-542

[4] S.H. Tone, D.C.H. Yang, On the Generation of New Lobe Pumps for Higher Pumping Flowrate, Mech. Mach. Theory 35 (2000) 997-1012

[5] S.H. Tone, D.C.H. Yang, The Specific Flowrate of Deviation Function Based Lobe Pumps - Derivation and Analysis, Mech. Mach. Theory 37 (2002) 1025-1042

[6] S.H. Tone, D.C.H. Yang, Rotor Profiles Synthesis for Lobe Pumps with Given Flowrate Functions, ASME J. Mech. Des. 127 (2005) 287-294

[7] Y.W. Hwang, C.F. Hsieh, Study on High Volumetric Efficiency of the Roots Rotor Profile with Variable Trochoid Ratio, Proc. IMechE, Part C: J. Mech. Eng. Sci. 220 (2006) 1375-1384
[8] C.F. Hsieh, Y.W. Hwang, Study on the High-Sealing of Roots Rotor with Variable Trochoid Ratio, ASME J. Mech. Des. 129 (2007) 1278-1284

[9] L.C. Valdès, B. Barthod, Y.L. Perron, Accurate Prediction of Internal Leaks in Stationary Dry Roots Vacuum Pumps, Vacuum 52 (1999) 451-459

[10] A. Burmistrov, L. Belyaev, P. Ossipov, M. Fomina, R. Khannanov, Combined Experimental and Calculation Study of Conductance of Roots Pump Channels, Vacuum 62 (2001) 331-335

[11] G. Houzeaux, R. Codina, A Finite Element Method for the Solution of Rotary Pumps, Comput. Fluids 36 (2007) 667-679

[12] W. Strasser, CFD Investigation of Gear Pump Mixing Using Deforming/Agglomerating Mesh, ASME J. Fluids Eng. 129 (2007) 476-484

[13] D. Del Campo, R. Castilla, G.A. Raush, P.J. Gamez Montero, E. Codina, Numerical Analysis of External Gear Pumps Including Cavitation, ASME J. Fluids Eng. 134 (2012) 081105

[14] H. Ding, F.C. Visser, Y. Jiang, M. Furmanczyk, Demonstration and Validation of a 3D CFD Simulation Tool Predicting Pump Performance and Cavitation for Industrial Applications, ASME J. Fluids Eng. 133 (2011) 011101

[15] F.L. Litvin, Gear Geometry and Applied Theory, Prentice Hall, New York, 1994 